\title{
Espantapájaros de Oliverio Girondo Un flâneur a contrapelo*
}

\author{
Macarena Roca**
}

\section{Resumen}

Este estudio revisa las nociones de vanguardia presentes en el poemario de 1932 a partir de la figura del flâneur latinoamericano, el que callejea desde el margen histórico de la ciudad y desde la mezcla de culturas que habita. Este produce un contradiscurso a la modernidad desmantelando las normas sociales y la noción de sujeto decimonónico. El hablante urbano de Espantapájaros manifiesta un permanente rechazo a las convenciones lingüísticas y un animismo cósico frente a la existencia.

Palabras clave: vanguardia - flâneur - contradiscurso - modernidad periférica.

\section{Oliverio Girondo`s Scarecrow. A flâneur against the grain}

\begin{abstract}
This study goes through the avant-garde notions present in the 1932 collection of poems from a latinamerican flâneur that walks about from the historic limit of the city and from the mixture of cultures that inhabits. It produces a speech deconstruction to modernity dismantling the social rules and the notion of the nineteenth-century subject. The Espantapájaros urban speaker expresses a continuing rejection to the linguistic conventions and a spirituality of the object towards existence.
\end{abstract}

Key words: avant-garde - flâneur - speech deconstruction - peripheral modernity.

Recibido: 04-01-2013 Aceptado: 23-08-2013

\footnotetext{
Esta investigación es parte de la suficiencia investigadora conducente al título de doctor, Universidad de Salamanca, España.

** Chilena, Magíster en Literatura Hispanoamericana y Chilena, Universidad de Chile. Profesora Asistente de la Facultad de Artes Liberales, Universidad Adolfo Ibáñez, Santiago, Chile, mroca@ uai.cl
} 


\section{Introducción: modernidad y contradiscurso}

El hablante de Espantapájaros posee similitudes en el modo de operar del flâneur del S.XIX, pero a diferencia de la actitud distante que a este le permitía elaborar un juicio crítico sobre lo que observaba, el flâneur girondoniano es atrapado por su emotividad, perdiendo diferenciación con el objeto observado. No se congracia con la modernidad y replica a los que viven a favor de los fulminantes cambios económico-sociales que se han suscitado desde el siglo XIX. Sin embargo, su criticismo lo lleva a un estado progresivo de pérdida de objetividad, situándolo en los confines de sus afectos. Esta distinción de sujetos urbanos no es paradójica, ya que la modernidad contiene y contrasta dos modernidades distintas y en permanente conflicto (Calinescu, 2003). Una, es la etapa en la historia de la civilización occidental; la otra, el concepto estético. Las relaciones entre ellas son hostiles, pero sus diferencias influyen en la articulación de ambas. La modernidad, como el producto del progreso científico y técnico de la revolución industrial, de los cambios económicos y sociales traídos con el capitalismo, el culto a la razón, el pragmatismo, la necesidad de éxito, y la idea de libertad espacio-temporal, es sostenida por la clase burguesa. La otra modernidad es la que llega a las vanguardias, la que siente rechazo por los valores de esa clase media, la de la actividad rebelde, contestataria. Lo que define a esta modernidad estética cultural es el rechazo al afán consumista, al progresismo, y al racionalismo ilustrado; es decir, las categorías económica, social y epistemológica con que la burguesía se desarrollaba.

La vanguardia toma todos sus elementos de la tradición moderna, pero al mismo tiempo los amplía, exagerándolos, y "los sitúa en los contextos más inesperados, haciendo que sean a menudo completamente irreconocibles" (2003: 105). Representa en la incorporación y uso de los mecanismos propios de la modernidad un contra-discurso a lo que hegemónicamente ha sido entendido como moderno. Modernidad y vanguardia no deben confundirse. Hay continuidades, rupturas y traslados, pero nunca una homologación de términos.

Oliverio Girondo, desde inicios de la década del veinte hasta fines de la del treinta, desarrolla dos frentes en su metapoesía: el primero, el hastío ante una tradición museificada e intolerante que ha tapiado con su peso histórico la oxigenación de un arte nuevo y propio. La tradición cultural ha negado el arte americanista y la reflexión estética universal. 
Girondo prefiere que el arte dé balbuceos originales antes que palabras ampulosas conocidas: "¡Si buena parte de nuestros poetas se convenciera de que la tartamudez es preferible al plagio!" (1999: 71). El segundo frente, también ligado a la tradición cultural, es la necesidad de renovar los principios epistemológicos. Dice no a la razón como único método de aproximación, ya que mediante la incorporación de otros estadios mentales, como la imaginación y la intuición, la realidad se expande y multiplica. Estos dos frentes (integración y amplificación), unidos al rechazo del estilo de vida burgués, caracterizan al hablante flâneur del poemario del treinta y dos. Si bien no hay referencias en Espantapájaros a una metrópolis en particular, se encuentra un modo de ser y vivir urbano (observador afectado, discontinuidad de la mirada, fragmentación de las imágenes, rápido despacho de lo conjeturado) que se integra a los temas y a las estrategias discursivas del poeta. El flâneur de Espantapájaros desestructura los significados de la modernidad histórica y, además lo hace desde un escenario periférico y americano.

\section{Flâneur girondoniano y condiciones históricas de aparición}

El impacto de las transformaciones tiene una dimensión subjetiva que no es posible soslayar. Esta para Sarlo, es la percepción que en muy poco tiempo cambia el modo de ver y entender la ciudad de Buenos Aires. El locus que preservaba los recuerdos de infancia ha cambiado sustancialmente para convertirse en una metrópolis de diversidades culturales y de gran crecimiento económico. Buenos Aires es una modernidad periférica porque responde a una cultura de mezcla, una cultura afincada en el lindero de una época y de sus tradiciones. Es "modernidad europea y diferencia rioplatense, aceleración y angustia, tradicionalismo y espíritu renovador, criollismo y vanguardia" (Sarlo, 2003: 15).

Nostalgia y denuncia se concretan a través de la expresión vanguardista que representa el cruce de dos tendencias: ultraísmo y criollismo, renovación estética y memoria. Esta propuesta busca entender la cultura rioplatense a partir de tres condiciones: la llegada de esta modernidad en crisis proveniente de Europa, el reacondicionamiento producido por Latinoamérica, y las propuestas personales ligadas a problemáticas individuales. "Coexisten elementos defensivos y residuales junto a los 
programas renovadores; rasgos culturales de la formación criolla al mismo tiempo que un proceso descomunal de importación de bienes, discursos y prácticas simbólicas" (Sarlo, 2003: 28).

Sarlo observa que esta ciudad moderna latinoamericana ${ }^{1}$ hace posible la presencia del flâneur, un sujeto urbano que mira de forma crítica y anónima mientras callejea. Este personaje representa en Argentina "más que un concepto demográfico y urbanístico, una categoría ideológica y un mundo de valores" (2003: 16). La ciudad de Buenos Aires presenta una ampliación del concepto de flâneur francés del siglo XIX, ya que es un sujeto que mira desde un margen, se detiene en el (des)encuentro de las culturas, y desde allí produce un discurso que revela incomodidad y desconcierto.

Lo moderno es la nueva percepción de lo real, un momento de la humanidad en que lo sucesivo da lugar a lo inmediato y simultáneo. Un tiempo en el que el espacio histórico es reemplazado por el espacio urbano, así como la tradición y la costumbre por el instante y lo nuevo. Sin embargo, en Latinoamérica, junto a esta visión de corte fue un rasgo común entre los poetas la reflexión sobre las culturas nacionales, lo cual mayoritariamente se manifestó a través de artículos polémicos, textos teóricos, y trabajos metapoéticos².

Durante la década del veinte Latinoamérica tuvo un despertar de actitudes poéticas vanguardistas (manifiestos, proclamas, revistas locales, cartas abiertas) debido a la influencia de modelos provenientes de Europa. En el caso de Oliverio Girondo, amigo de Jules Supervielle, Ramón Gómez de la Serna y Jean Cassou, nos encontramos con un poeta cuya obra supo incorporar y traducir la nueva estética mediante la actualización de lo nacional y un proyecto poético personal. Sus viajes constantes a Europa y su conocimiento de diversas lenguas le permitió comprender la cultura como un hacer universal y no partidista ni regional. En su poesía, principalmente en sus dos primeros libros-Veinte poemas y Calcomanías-, la actitud de ruptura con las estéticas pasadas está fundada en el agotamiento anímico producido por los cánones modernistas de América. Sin embargo, y siguiendo esta cultura de mezcla,

1 Ciudades como Buenos Aires, Sao Paulo, Ciudad de México.

2 V. Verani, Hugo. Las vanguardias literarias en Hispanoamérica. México, Fondo de Cultura Económica, 1990. 
en Campo Nuestro (Girondo, 1942) no es posible hacer una separación entre criollismo y cosmopolitismo ${ }^{3}$. Su poética está entre ambas líneas de creación, ya que incorpora las técnicas vanguardistas con lenguaje y expresiones regionales, ampliando así el alcance del castellano. Hugo Verani considera de importancia "recordar que el criollismo, tendencia que aspira a desentrañar la esencia de la argentinidad, se desenvuelve precisamente dentro de la misma vanguardia cosmopolita" (1990: 46). En otras palabras, no es posible pensar la vanguardia latinoamericana como una mera continuación de la vanguardia europea ${ }^{4}$.

Girondo participa activamente con el periódico literario Martín Fierro. En 1924, el mismo año de Carta abierta a la Púa (aparecida un año después en la segunda edición de Veinte poemas), publicará el ya conocido manifiesto martinfierrista, en donde atacará retóricas pasatistas y el endurecimiento de la sensibilidad e imaginación. Junto a este periódico, Proa, Klaxon y Revista de Antropofagia (argentina la primera, brasileñas las dos últimas), cambiaron el panorama cultural durante el segundo decenio del siglo XX en el continente. Martín Fierro tuvo invitados internacionales: Picasso, Braque, Apollinaire, Morand. La revista no publicó exclusivamente poesía, sino artículos sobre cine, fonógrafo, pintura y arquitectura. Abarcó todas las áreas que estaban tocadas por la nueva sensibilidad y que se encontraban relacionadas con las nuevas técnicas de producción. La revista reprodujo arte latinoamericano, como por ejemplo, pinturas de Diego Rivera, poemas de Xavier Villaurrutia y gráficas de Xul Solar. El sello integracionista de Martín Fierro estuvo dado por Girondo, uno de sus grandes colaboradores (y sostenedores económicos). Junto a él, la revista produce un ambiente de efervescencia artística, aspecto propicio para la aparición de las nuevas poéticas en el Río de la Plata. En 1927, la revista se disuelve debido a que algunos miembros apoyaron políticamente la candidatura de Hipólito Irigoyen, lo cual atentó contra el principio apolítico fundacional de la publicación.

3 Gaspar Pío del Corro establece que la literatura de la década del veinte recogió conjuntamente dos influjos de origen diverso: por una parte, la crisis de las formas literarias (cuyo centro principal estaba en Europa) y, por otra, la crisis de los mitos nacionales americanos. Por esto, él aborda el texto Espantapájaros como un espacio de la no-conformidad con el mundo de la modernidad social argentina.

4 Guillermo de Torre, con su ensayo "Madrid, meridiano intelectual de Hispanoamérica" (La gaceta literaria del 15 de abril de 1927), iniciará un candente debate sobre la sujeción cultural que España tiene sobre Latinoamérica. Sus palabras sucitaron variadas respuestas provenientes de escritores y revistas de la región que defendieron, con vehemencia y humor negro, la autonomía cultural. V. Alemany, Carmen. La polémica del meridiano intelectual de Hispanoamérica (1927). Estudio y textos (1998). 
Desde ese momento, el poeta comienza un trabajo poético personal ligado a la publicación de sus libros en Argentina.

Hacia fines de los años treinta, publica artículos en La Nación donde ataca vehementemente la tradición colonialista de Europa y se sitúa a favor de la autonomía nacional. En textos como El mal del siglo (1937), el poeta muestra una ácida postura sobre la decadencia de la modernidad y los peligros de los nuevos sistemas políticos y económicos, así como en Nuestra actitud ante el desastre (1940) denuncia el peligro de la influencia del nacional-socialismo en Argentina.

\section{Contradiscurso o estética del rechazo}

Girondo desarrolla una dialéctica de rechazo y asimilación de la tradición ${ }^{5}$. En un membrete escribe: "Los únicos brazos entre los cuales nos resignaríamos a pasar la vida, son los brazos de las Venus que han perdido los brazos" (1999: 65). Utilizando formas coloquiales introduce lo cotidiano en el arte y desarrolla una palabra subersiva al orden tradicional y consuetudinario. Mediante vehemencia y sarcasmo explicita su malestar con la continuidad de un arte socialmente aceptado. Esta desarticulación de la tradición no solo es ruptura, sino también modificación e incorporación. "un álbum de retratos que [el artista] hojea de vez en cuando, para descubrirse a través de un antepasado...o reírse de su cuello y de su corbata" (1999: 306).

La modificación del horizonte estético y la ruptura frente a la representación de la realidad son problemáticas propias de las primeras décadas del siglo XX y se hallan sustentadas en la capacidad destructiva del artista ${ }^{6}$. Su destrucción es un acto con pleno sentido, y lleva la marca indeleble del humor. El humor sería, de este modo, la forma más radical de desconfiguración. A través de él el artista puede romper con la realidad inmediata y entrar en la configuración interna de lo que observa.

5 Dentro de los estudios exegéticos, Jorge Schwartz, Beatriz Sarlo y Patricio Rizzo postulan una mirada de encuentro entre culturas. Para Schwartz es una contradicción estructurante, para Sarlo una condición latinoamericana por ser cultura periférica, y para Rizzo el eje de la postulación poética universalista del poeta.

6 Aldo Pellegrini, poeta surrealista y amigo de Girondo, postula la categoría de la "destrucción" como la actitud más creadora y vitalista del arte. A mediados de la década del cincuenta, publica un breve ensayo en donde las ideas allí concebidas se inscribirán en la tradición de la ruptura postulada por Octavio Paz años después. V. Fundamentos de una estética de la destrucción (1957). 
En el poema 13 el hablante se muestra en la forma de un golpe, de una patada, es decir, una fuerza física que violenta lo real. La patada es hiperbolización humorística del rechazo que el hablante tiene sobre la sensibilidad acomodada. Un rechazo visceral al stablishment del sujeto.

Hay días en que yo no soy más que una patada (...) ¿Se detiene una calva?... Allá va por el aire hasta ensartarse en algún pararrayos. ¿Un automóvil frena al llegar a una esquina? Instalado de una sola patada en alguna buhardilla. ¡Al traste con los frascos de las farmacias, con los artefactos de luz eléctrica, con los números de las puertas de calle! (...) Necesito derrumbar las cornisas, los mingitorios, los tranvías. Necesito entrar - ja patadas!- en los escaparates y sacar -ja patadas!todos los maniquíes a la calle (...) A patadas con el cuerpo de bomberos, con las flores artificiales, con el bicarbonato. A patadas con los depósitos de agua, con las mujeres preñadas, con los tubos de ensayo. (1999: 94).

Junto a la mirada destructiva hay nuevas concepciones sobre la construcción de la personalidad. El sujeto tradicionalmente era una figura discursiva cuya identidad unificada y racional era incuestionable. Un sujeto de carácter universal, cartesiano, con plena conciencia y voluntad, dueño de sus pensamientos y de sus actos.

El poema 8 nos deja ver la fragmentación de la personalidad y la autoconciencia de ella:

Yo no tengo una personalidad; yo soy un cocktail, un conglomerado, una manifestación de personalidades. En mí la personalidad es una especie de forunculosis anímica en estado crónico de erupción; no pasa media hora sin que me nazca una nueva personalidad. Desde que estoy conmigo mismo, es tal la aglomeración de las que me rodean, que mi casa parece el consultorio de una quiromántica de moda (...) ¡Imposible lograr un momento de tregua, de descanso! ¡Imposible saber cual es la verdadera! (...) ¿Qué clase de contacto pueden tener conmigo -me pregunto- todas estas personalidades inconfesables, que harían ruborizar a un carnicero? (86).

La ebullición de identidades nos conduce a un tema mayor y que es condición social desde la modernidad: la pérdida de unidad del sujeto. 
Desde la calle (Veinte Poemas y Calcomanías), el flâneur girondoniano entra a las habitaciones de la casa y se sitúa en los pliegues de la vida privada para exhibir la inhumanidad con que el individuo realiza su vida. Ya no solo camina por la ciudad observando el actuar de los sujetos en los espacios públicos, sino que ahora es un voyeur cósmico: está en todas partes (ubicuidad) y transfigurado en innumerables identidades (transmigración).

Es así como surge la problemática de la disyuntiva: “¿Mearé o beberé agua?" La condición de posibilidad es consecuencia de "la estructura agónica de la modernidad periférica. La oscilación entre expulsar o incorporar, entre asumir o abandonar" (Antelo, 1999: 19-89). El epígrafe del poemario del 22, dirigido a La Púa, dice:

Con la certidumbre reconfortante de que en nuestra calidad de latinoamericanos, poseemos el mejor estómago del mundo, estómago ecléctico, libérrimo, capaz de digerir, y de digerir bien, tanto unos arenques septentrionales o un kouskous oriental, como una becasina cocinada en la llama o uno de esos chorizos épicos de Castilla. (1999: 4).

Expulsar o incorporar son opciones que presuponen el drama de una identidad escindida que oscila entre lo local y lo extranjero, la tradición y lo propio, lo anterior y lo nuevo. Girondo no resuelve las tensiones de esta dicotomía, sino que las patentiza. El caligrama que inaugura el poemario nos enfrenta a una verdad transversal: el no saber. La conjugación del verbo, desde su negación, anuncia la opacidad con la que el hablante abordará la realidad. Un no-saber que busca acabar con el conocimiento empírico de la realidad. El no-saber de Espantapájaros genera un campo inexplorado de posibilidades.

La "extimidad" del poema caligramático de Girondo está asociada con la exposición de lo íntimo del hablante. Su no-saber es muestra del nihilismo existencial que el sujeto asume en medio de la sociedad culturalmente atávica. La desinencia pronominal del verbo ejemplariza la monotonía del estar siendo. El vaciamiento del significado culmina en el croar de las ranas que nada dicen y nunca callan. La redundancia produce el desgaste semántico. Este poema problematiza visual y sintácticamente el conflicto de la sociedad moderna y su contestación vanguardista. Es una representación reflexiva sobre el sujeto burgués construido a partir de su filisteísmo (Lám. 1). 
Espantapájaros nos muestra un flâneur que (a diferencia del baudelariano que observa desde determinados lugares) transita en un entre-lugares (Antelo, 1999). Es un entre-lugar de lo real y metafísico, de lo sublime y lo abyecto. El sujeto llama a ampliar la existencia mediante la imaginación: "al sentir deseos de viajar, tomamos un boleto en una agencia de vapores, en vez de metamorfosear una silla en transatlántico" (1999: 72). Estamos ante un imaginario de la inestabilidad y el extrañamiento. Afirma cuando niega, y niega cuando afirma. El siguiente membrete muestra esta aporía: "En arte, en poesía, nada más importante que el recuerdo, ni más indispensable que saber olvidar" (1999: 67).

El arte es acción 7 . Contra la interpretación simbólica de la poesía tradicional, apela por un lenguaje cotidiano. Introduce lo prosaico: alusiones sexuales, objetos ramplones. Ejecuta distintas voces y parodia formas de vida reconocibles. El hablante borra distinciones nominales y desplaza a la razón de su lugar central. El mundo de Espantapájaros está en tensión entre el imperativo de la posibilidad y las respuestas parciales. El mundo aludido penetra en el hablante y su constitución adquiere dimensiones cósmicas en un permanente vaciamiento. El hablante padece la discontinuidad y está expuesto constantemente a nuevos estímulos. Hay saltos, abandonos, repuntes, escamoteos. Esto se aúna al autorreconocimiento de la fragmentación del hablante. Junto a la multifocalidad se encuentra el nerviosismo y la indecisión con que precariza su existencia.

Mis nervios desafinan con la misma frecuencia que mis primas. Si por casualidad, cuando me acuesto, dejo de atarme a los barrotes de la cama, a los quince minutos me despierto, indefectiblemente, sobre el techo de mi ropero. En ese cuarto de hora, sin embargo, he tenido tiempo de estrangular a mis hermanos, de arrojarme a algún precipicio y de quedar colgado de las ramas de un espinillo. (84)

El hablante vive con pulsiones ocultas. Además, padece de afecciones físicas: "Mi digestión inventa una cantidad de crustáceos, que se entretienen en perforarme el intestino (...) Todavía cuando llueve me

7 Esta energía en el verso es transversal a la vanguardia. Vicente Huidobro manifestó: Nada de paseos indecisos. ¡La bolsa o la vida! La poesía es un asalto, un shock producido por el vitalismo de la palabra poética. Cf. Manifiesto Tal Vez (1921). 
duele la pierna que me amputaron hace tres años. Mi riñón derecho es un maní. Mi riñón izquierdo se encuentra en el museo de la Facultad de Medicina", de obsesiones psicológicas: "Los márgenes de los libros no son capaces de encauzar mi aburrimiento y mi dolor. Hasta las ideas más optimistas toman un coche fúnebre para pasearse por mi cerebro", y de un sino oscuro: "He perdido a la lotería, hasta las uñas de los pies, y en el instante de firmar mi acta matrimonial, me di cuenta de que me había casado con una cacatúa" (84). Estamos ante un sujeto afectado, temeroso, desconfiado, que termina señalando que "en estas condiciones, creo sinceramente que lo mejor es tragarse una cápsula de dinamita y encender, con toda tranquilidad, un cigarrillo". ${ }^{8}$

El flâneur girondoniano no recoge signos para construir identidades, sino para desmantelar las identidades ya establecidas, para desarmar significados. La mirada va cargada de juicios apriorísticos que desestructuran lo observado. Es un flâneur que desarticula la modernidad en cuanto proyecto de progreso indefinido y en cuanto sistema de vida racional y unívoco.

En el acto de entregar su tarjeta, por ejemplo, los visitantes se sacaban los pantalones, y antes de ser introducidos en el salón, se subían hasta el ombligo los faldones de la camisa. Al ir a saludar a la dueña de casa, una fuerza irresistible los obligaba a sonarse las narices con los visillos, y al querer preguntarle por su marido, le preguntaban por sus dientes postizos. (1999, 79)

La vanguardia histórica presentó un permanente elogio al inconformismo, "fue más radical que la modernidad, menos flexible y tolerante. Más dogmática, tanto en el sentido de autoafirmación como en su [inherente] autodestrucción" (Calinescu, 2003: 104).

\section{Animismo y proyección sentimental}

La multifocalidad del hablante se inicia en la hipersensibilidad con que se fusiona a otros individuos. Interactúa orgánicamente con todo, ya sean seres vivos u objetos inanimados. La desarticulación de lo real pasa

8 Si bien Girondo expulsa la continuidad simbólica de Espantapájaros, no es posible obviar la existencia de una lógica interna El nuevo orden de la obra inorgánica o vanguardista no se encuentra en la continuidad de las partes, sino en la lógica del ensamblaje. V. Bürger, Peter. Teoría de la vanguardia. 
por una estrategia animista en el poemario y este se encuentra tanto en el sujeto como en las cosas que lo rodean.

Los objetos son animados por un espiritualismo proveniente de la mirada del hablante. En el poema 19, se ve un nuevo rostro en los objetos cotidianos: “¿Que las poleas ya no se contentan con devorar millares y millares de dedos meñiques? ¿Que las máquinas de coser amenazan zurcirnos hasta los menores intersticios? ¿Que la depravación de las esferas terminará por degradar a la geometría?"(102).

Girondo reflexiona acerca de la visión deshumanizada que posee el hombre de la metrópolis, y, para evidenciar esa falta de solidaridad, cancela los límites entre sujetos y objetos. Esta fusión de entes, la ausencia de límites diferenciadores, es lo que conforma el paisaje urbano en Espantapájaros. En este sentido, "el globo ocular del voyeur obra como mediador entre el hombre y aquello que lo rodea". Así, se abolirá la distancia crítica u objetiva que estructura la condición de flâneur decimonónico. No es el hombre quien modifica el conocimiento de la ciudad, sino que esta es quien modela la interioridad y subjetividad del sujeto. El objeto actúa sobre el individuo y este se (des)configura "despersonalizado y fragmentario" (Schwartz, 1993: 148).

El sujeto se funde con el objeto ya que sobre este se proyecta anímicamente y forma una unidad indisoluble: "Que al salir a la calle, hasta los faroles te corran a patadas; que un fanatismo irresistible te obligue a prosternarte ante los tachos de basura y que todos los habitantes de la ciudad te confundan con un meadero" (1999: 107).

Es un proceso de desmarcación en el que desplaza la subjetividad hacia la conformación cósica de lo observado. Un efecto de deformación en donde el sujeto se refleja deformado en el objeto. Este se humaniza por la incorporación de atributos (formas físicas, sensaciones, pensamientos) $\mathrm{y}$, a la vez, lo humano se desplaza y se reduce a remedos genéricos o fantasmagorías.

En el poema 9 la sombra es conceptualizada como un simulacro de existencia, un espectro humano.

¿Nos olvidamos, a veces, de nuestra sombra o es que nuestra sombra nos abandona de vez en cuando? (...) Hemos subido las escaleras de cada noche, y sin embargo han pasado las horas, las semanas enteras, sin que notemos su presencia (...) Antes 
de atravesar las bocacalles esperamos que no circule ninguna clase de vehículo. En vez de subir las escaleras, tomamos el ascensor, para impedir que los escalones le fracturen el espinazo. (88)

Los hombres, cargados de características cósicas, son mecanizados y llevados a movimientos seriados y repetitivos. "Se perforan, se incrustan, se acribillan, se remachan, se injertan, se atornillan" (93). Para WentzlaffEggebert (2000) la cosalogía considera todos los ámbitos de la naturaleza, incluso los seres inanimados, los cuales son tratados como seres vivos. "Jamás se había oído el menor roce de cadenas. Las botellas no manifestaban ningún deseo de incorporarse. Al día siguiente de colocar un botón sobre una mesa, se le encontraba en el mismo sitio. El vino y los retratos envejecían con dignidad" (79).

Los objetos, por tanto, no son materialidades creadas por el hombre', sino que junto al valor cultural, tienen un vitalismo inherente que los hace compañeros del individuo en el mundo. Es precisamente la equiparación entre sujeto y objeto lo que nos permite hablar de un animismo cósico en Espantapájaros. Para Girondo no son representaciones ideológicas, sino cohabitantes del hablante.

La cosalogía propone que todos los objetos poseen un espíritu, están relacionados entre ellos e influyen sobre nuestro mundo interior. En Girondo las cosas no tienen un sentido utilitario, están liberadas de su existencia práctica. A través de ellas desenmascara situaciones y entrega un enaltecimiento moral: "Me repugna el bostezo de las camas deshechas" (84), [y] "que tu familia se divierta en deformarte el esqueleto, para que los espejos, al mirarte, se suiciden de repugnancia (...) y que te enamores tan locamente de una caja de hierro que no puedas dejar, ni un solo instante, de lamerle la cerradura" (107).

Maturo observa que lo externo es apoyo para consignar y fijar los acontecimientos internos (1996: 35). El hablante se margina del orden

9 Pablo Neruda en "Sobre una poesía sin pureza", se refiere a los objetos como plataformas de sentido para la nueva poesía. Sin embargo, la lectura de Neruda sobre el mundo cósico es diferente de la de Girondo. Para el poeta de Residencias, los objetos son representación del trabajo y el cansancio que el hombre imprime en ellos. "De ellos se desprende el contacto con el hombre y de la tierra como una lección para el torturado poeta lírico. Las superficies usadas, el gasto que las manos han infligido a las cosas, la atmósfera a menudo trágica y siempre patética de estos objetos, infunde una especie de atracción no despreciable hacia la realidad del mundo". En Caballo verde para la poesía 1 (octubre 1935). 
antropocéntrico y se sitúa en una homogeneización dignificante de todo lo que está en el universo. La ternura y complicidad que se desprende de los objetos (huella humana, proyección anímica del yo), nos muestran una fraternidad hacia los hombres mayor a la existente entre ellos. "De ahí ese optimismo de pelota de goma que me hace reír a carcajadas, del esqueleto de las bicicletas, de los ataques al hígado, de los limones; esa alegría que me incita a rebotar en las fachadas, en todas las ideas, a salir corriendo -jdesnudo!- por los alrededores para hacerles cosquillas a los gasómetros... a los cementerios" (103).

La vitalidad de los objetos lo deja al margen del protagonismo, eliminándole su distancia crítica y generándole una afectación anímica que termina por fragmentar su identidad. Nada hay constante, solo transitividad y posibilidad. Cualquier objeto puede poner en escena los secretos del universo: un farol, un escupidero, una escalera. Estamos en presencia de una conciencia fragmentaria del mundo en la que cada cosa adopta rasgos humanos.

El animismo encuentra su origen en las investigaciones de Emile Durkheim y Bronislaw Malinowski ${ }^{10}$, antropólogos que se dedicaron a estudiar culturas originarias, "en donde lo inanimado y lo animado no son divisiones tajantes, como lo son en la mente racionalista" (Rizzo, 2001: 46). Girondo, gran lector de etnografía y paleología, desarma las directrices provenientes de los centros de pensamiento europeos y de sus continuadores en América. "La poesía de Girondo en la década del '20 pone en una licuadora desacralizante el paisaje mundial con el paisaje latinoamericano" (48), es una ruptura con la tradición y los tradicionalistas, a la vez que aúna, en una literatura con proyección universal las problemáticas de la actualidad. Es la desacralización y la mezcla en cuanto condicionantes de un arte nuevo y proyectivo: "Nada puede darnos una certidumbre más sensual y un convencimiento tan palpable del origen divino de la vida, como el vientre recién fecundado de la Venus de Milo" (Girondo, 1999: 70).

A partir de la visión que percibe de la vieja Europa, abre espacios para la reflexión literaria latinoamericana. El uso del nosotros y ellos en el

10 Estos investigadores estudiaron culturas no antropocéntricas. En estas, el animismo festeja y enaltece a animales, objetos naturales, fenómenos climáticos, y les da gran importancia simbólica y mágica. 
caligrama inicial es analogable a un América y Europa 11. Critica el olvido e ignorancia que se tiene sobre Latinoamérica y su creación artística. Rechaza la condición de subalternidad con que Europa ve al continente. Realiza una "guerra a la levita" (Rizzo, 2001), combate irónico y punzante al modo de vida burgués importado de la modernidad decimonónica europea. Apela a la búsqueda de lo latinoamericano en cuanto tierra de fusiones, mezclas y (des)encuentros con Europa. Quiere autenticidad, diferencia, pero no por ello miradas particularistas desconectadas de un hacer cultural global: “¿Estupidez? ¿Ingenuidad? ¿Política?... ”Seamos argentinos" gritan algunos... sin advertir que la nacionalidad es algo tan fatal como la confirmación de nuestro esqueleto" (1999: 66).

América ha perpetuado las formas europeas sin ninguna mediación en el modelo. En un membrete, señala: “ ${ }_{i} E l$ arte es el peor enemigo del arte!... un fetiche ante el que ofician, arrodillados, quienes no son artistas" (1999: 68). Girondo realza el valor del riesgo sobre lo nuevo, lo diferente. Apuesta por la maravilla de descubrir lo distinto e indómito. Esto nos señala que el flâneur a contrapelo de Espantapájaros muestra hastío por formas literarias exógenas y por una moralidad templada y desligada de los avatares mundiales. Su obra muestra el desaliento que causa la tradición académica, la cual impide el avance de los nuevos lineamientos culturales de cada nación. Espantapájaros es una figura que busca espantar el dogmatismo y la actitud enmudecida del sujeto.

\section{Conclusiones}

El flâneur del s. XIX (ubicuo y voyeur) se caracterizaba por mantener la distancia crítica y la elección de un objetivo en torno a los signos que observaba, en cambio, el flâneur de Espantapájaros desarticula el conocimiento sobre lo real a partir de la ampliación perceptiva que le otorga la imaginación. Es una voz que vive afectada anímicamente, y sus cambios de humor exhiben tedio ante la determinación y la rutina. En vez de recoger un signo en la ciudad y construir una historia -actividad fetichista-, desmonta la realidad para entregarnos fragmentos que posibilitan nuevos rostros de lo conocido. Trabaja sobre la posibilidad prolífica, la indeterminación o promiscuidad de historias posibles y paralelas. Su ubicuidad se apoya en su facultad imaginativa y su constante metempsicosis vital. Su observación no es metódica ni racionalmente crítica, sino extremadamente subjetiva e hipersensible. 
Estamos en presencia de la ampliación del mentado flâneur en el marco de la literatura rioplatense. Para Sarlo, esta condición está dada debido a que el sujeto en esa modernidad periférica, miraba y enunciaba desde un margen. Estaba detenido en el encuentro de dos culturas y de dos épocas y, desde allí, producía un discurso de ruptura, de incorporación y de novedad (entendido como cultura de mezcla). Todo esto hace que la producción literaria de Girondo revele incomodidad y desconcierto. Su obra está vinculada con las problemáticas del cambio y su legitimación en Latinoamérica, aspectos que, para la mayoría de los exegetas, se encuentran en el debate estético y los enfrentamientos ideológicos de las primeras décadas del siglo XX. Con Girondo se abre el camino de la vanguardia poética en la Argentina. Introduce cosmopolitismo, una apertura en los contenidos de las producciones poéticas y un trabajo de equipo y de difusión en torno a las revistas literarias vanguardistas.

El hablante del poemario del treinta y dos es un flâneur a contrapelo ya que desde una construcción literaria moderna rebate los correlatos que trae consigo la cultura europea (políticas fallidas, debacles económicas, desaciertos sociales y conflictos raciales). Sin embargo, Girondo no postula una vuelta a lo vernáculo, a las tradiciones nacionales o a los arquetipos folclóricos. La modernidad urbana en Girondo se encuentra desvinculada del propósito de recuperación de una ciudad pretérita e imaginaria, como fue el caso del Buenos Aires de Borges o Fernández.

Girondo nos lega una obra que contesta con irreverencia y desacralización a la tradición artística europea y sus acríticos continuadores regionales. Su proyecto permite reflexionar sobre el quehacer artístico y escritural del latinoamericano, tal como fue evidenciado en aquellos años en los números de Martín Fierro, su prólogo Pintura Moderna (1936), y sus ensayos Nuestra actitud ante Europa (1937) y Nuestra actitud ante el desastre (1940). Estos ensayos, junto a su producción poética, nos participan los objetivos primordiales de su trabajo poético: la desarticulación de la modernidad europea y la valoración del arte latinoamericano. 
Anexos

Lámina 1

Yo no sé nada

$T$ í no sabes nada

Ud. no sabe nada

El no sabe nada

Ellus no saben nada

Ellas no saben nada

Uds. no saben nada

Nosotros no sabemos nada.

La desorientación de mi generación tienc su explicación en la dirección de nuestra educación, cuy a idealización de la acción, era - $j$ sin discusión!una mistificación, en contradicción con nuestra propensión a la meditación, a la contemplación y

a la masturbación. (Gutural.

lo más guturaimente que

se pueda.) Creo que

creo en lo que creo

que no creo. Y creo

que no creo en lo

que creo que creo.

"Cantar de las ranas"

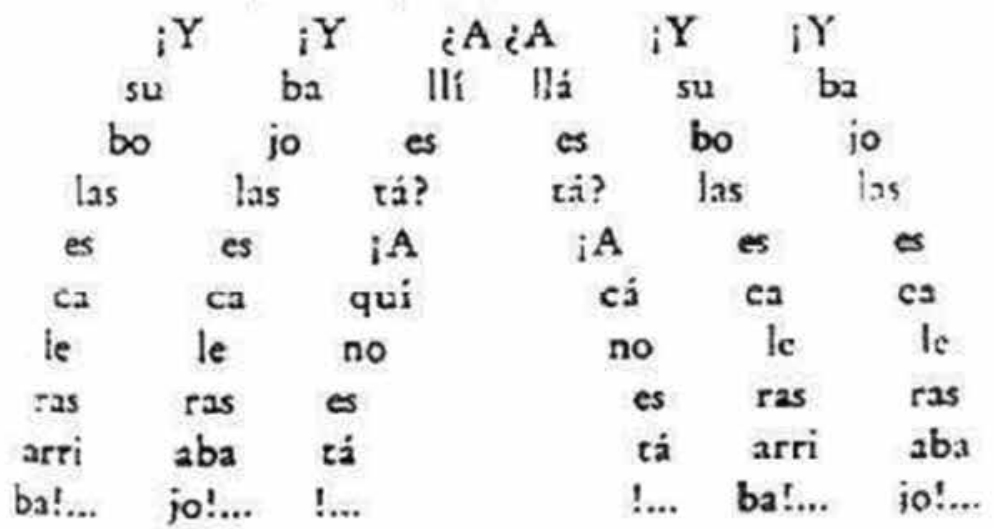




\section{Referencias bibliográficas}

Antelo, R. (1999). "Estudio filológico preliminar" en GIRONDO, Oliverio. Obra completa. Madrid: Universitaria, 27-89.

Calinescu, M.(2003). Cinco caras de la modernidad. Madrid: Neometrópolis.

Del Corro, G. (1976). Oliverio Girondo, los límites del signo. Buenos Aires: Fernando García Cambeiro.

Girondo, O. (1999). Obra Completa. Madrid: Universitaria.

Marún, G. (1995). “Efectos de la modernidad burguesa argentina en la modernidad literaria (1875-1880)", en La modernidad literaria en España e Hispanoamérica. Salamanca: Ediciones USAL, 13-9.

Maturo, G. (1996). La mirada del poeta. Ensayo sobre el conocimiento y el lenguaje poético. Buenos Aires: Corregidor.

Rizzo, P. (2001). El lugar de Oliverio Girondo. Buenos Aires: Corregidor.

Sarlo, B. (2003). Una modernidad periférica. Buenos Aires 1920 - 1930. Buenos Aires: Nueva visión.

Schwartz, J. (1991). Las vanguardias latinoamericanas. Textos programáticos y críticos. Madrid: Cátedra. - (1993). Vanguardia y cosmopolitismo en la década del veinte. Oliverio Girondo y Oswald de Andrade. Buenos Aires: Beatriz Viterbo.

Wentazlaff-Eggebert, H. “La cosa primero, el hombre después. Sobre la cosalogía en la vanguardia hispánica" en Ciberletras. Revista de crítica literaria y de cultura. URL: <http: / / www.lehman.cuny.edu/ciberletras/v08/ wentzlaff. html > Consultado el 12 de abril de 2005. 
